\title{
AVALIAÇÃO QUÍMICA E FÍSICA DE COMPONENTES DO BARU (Dipteryx alata Vog.) PARA ESTUDO DA VIDA DE PRATELEIRA ${ }^{1}$
}

\author{
Aline Medeiros Alves², Aline Luiz de Mendonça ${ }^{3}$, Márcio Caliari ${ }^{3}$, Raquel de Andrade Cardoso-Santiago ${ }^{2}$
}

\section{ABSTRACT \\ CHEMICAL AND PHYSICAL EVALUATION \\ OF BARU (Dipteryx alata Vog.) COMPONENTS FOR SHELF LIFE STUDY}

Agroecology, a science that studies productive relations between man and nature, and whose goal is ecological, economic, social, cultural, political, and ethical sustainability, has been increasingly used as a tool for social and cultural transformation. Within that perspective, the Brazilian Cerrado provides fruits such as baru, which is highly genetically variable, but also widely used as a source of income by the regional population. The objective of this study was to evaluate the chemical and physical characteristics of baru pulp, along a 181-day storage period. For that purpose, weight and size analyses, centesimal analysis, monitoring of changes, and sensorial analysis of dry biscuits, in which $25 \%$ of the wheat flour was replaced by baru pulp, were carried out. Physical characteristics such as weight, length, and width did not present significant differences, during the storage period. The level of total sugars and reducers increased during the storage period, unlike the tannin level, which decreased. Baru pulp may be considered an important source of sugars and dietary fiber. In addition, the biscuits obtained satisfactory scores for both taste and appearance, on the acceptability test, and their nutritional quality increased.

KEY-WORDS: Baru; pulp; physical and chemical analyses; kinetics; sensorial analysis.

\section{INTRODUÇÃO}

O termo "Agroecologia” é entendido como um conjunto de princípios e técnicas, que visam a reduzir a dependência de energia externa e o impacto ambiental da atividade agrícola, produzindo alimentos mais saudáveis e valorizando o homem do campo, sua família, seu trabalho e sua cultura. Nesta lógica, o baru (Dipteryx alata Vog.), árvore da família Leguminosae, disseminada no bioma Cerrado, faz parte do grupo das espécies nativas usadas pela po-

\section{RESUMO}

A Agroecologia, ciência dedicada ao estudo das relações produtivas entre homem e natureza, visando sempre à sustentabilidade ecológica, econômica, social, cultural, política e ética, vem sendo utilizada como ferramenta de transformação social e cultural. Nesta perspectiva, o Cerrado brasileiro possui frutos como o baru, que, apesar da alta variabilidade genética, é muito utilizado pela população regional, como fonte de renda familiar. Portanto, este trabalho acompanhou as características químicas e físicas da polpa do baru, durante 181 dias de armazenamento. Foram realizadas análises de peso, tamanho, composição centesimal, acompanhamento das alterações e análise sensorial de biscoitos formulados com $25 \%$ de substituição da farinha de trigo pela polpa de baru. Características como peso, comprimento e largura não apresentaram diferenças significativas, durante o período de estocagem. O teor de açúcares totais e redutores aumentou, durante o período de armazenamento, ao passo que o teor de taninos sofreu redução. A polpa do baru pôde ser considerada fonte importante de açúcares e fibra alimentar. Os biscoitos obtiveram notas satisfatórias no teste de aceitabilidade, tanto para sabor quanto para aparência, e verificou-se melhora na qualidade nutricional.

PALAVRAS-CHAVE: Baru; polpa; análises físico-químicas; cinética; análise sensorial.

pulação regional, como fonte de renda familiar (Sano et al. 2004). Em média, são produzidos de 2.000 a 6.000 frutos por planta (Soares Júnior et al. 2007). É uma das espécies mais promissoras para cultivo, devido a seus usos múltiplos, dentre eles alimentar, madeireiro, medicinal, industrial, paisagístico e na recuperação de áreas degradadas. Constitui uma das poucas espécies que apresentam frutos com polpa carnosa durante a estação seca, sendo importante para a alimentação da fauna, nesta época (Sano et al. 2004).

1. Trabalho recebido em maio/2009 e aceito para publicação em ago./2010 (n registro: PAT 6343/ DOI: 10.5216/pat.v40i3.6343).

2. Universidade Federal de Goiás, Faculdade de Nutrição, Goiânia, GO, Brasil.E-mails: amedeiros87@gmail.com, rcardosu@fanut.ufg.br.

3. Universidade Federal de Goiás, Escola de Agronomia e Engenharia de Alimentos, Setor de Engenharia de Alimentos, Goiânia, GO, Brasil.E-mails: alineluiz.senai@sistemafieg.org.br, macaliari@ig.com.br. 
O barueiro frutifica apenas durante três meses do ano, geralmente de agosto a outubro, e possui alguns componentes, como os taninos, que se perdem durante a estocagem, a qual, por sua vez, não pode ser realizada de qualquer maneira e nem por um período muito longo (Togashi \& Sgarbieri 1994).

A perda dos componentes deste fruto, durante o período de estocagem, pode ser avaliada e anunciada por meio do estudo destes componentes, com o auxílio de análises laboratoriais.

Com base nos fundamentos de cinética de reações e em conhecimentos de Ciência de Alimentos, pode-se conduzir uma avaliação da vida de prateleira. O primeiro passo para se estimar a vida de prateleira de um alimento é identificar as alterações que influenciam na sua qualidade. Realiza-se, então, um estudo dos componentes e do processo, para se determinar quais as alterações que terão maior impacto sobre a deterioração do produto. A cinética destas alterações determinará a vida de prateleira do produto, juntamente com as condições às quais o alimento será submetido, durante o período de estocagem (Azeredo \& Faria 2004).

Para um dado alimento, estocado sob condições definidas, cada alteração requer um tempo para torná-lo inaceitável. É importante que se defina qual será a alteração que, provavelmente, determinará a estabilidade daquele produto, sob aquelas condições de estocagem. A estimativa da vida de prateleira será feita, primeiramente, com base nesta alteração (Azeredo \& Faria 2004).

O baru é um fruto que vem sendo bastante explorado por pesquisadores, principalmente no que diz respeito à amêndoa, que representa, aproximadamente, $5 \%$ do fruto. Entretanto, trabalhos já determinaram a composição centesimal da polpa e da casca deste fruto, avaliando suas possibilidades tecnológicas, bem como suas potencialidades como ingrediente na indústria alimentícia, principalmente no que se refere às fibras (Azeredo \& Faria 2004, Rocha 2007).

$\mathrm{Na}$ alimentação humana, são utilizadas tanto a polpa quanto a amêndoa, na forma de doces, geleias e licores (Takemoto et al. 2001). Além disto, a farinha da amêndoa do baru pode ser utilizada como substituto do amendoim, existindo, ainda, outras possibilidades para sua utilização, como biscoitos, doces e pães, entre outros (Soares Júnior et al. 2007).

Alguns estudos relatam que os frutos do baru são fontes de carboidrato, proteína e lipídios. A pol- pa apresenta valor calórico de, aproximadamente, $300 \mathrm{kcal} / 100 \mathrm{~g}$, na sua maioria composta de carboidratos $(63 \%)$, predominantemente por amido, fibras insolúveis e açúcares. A amêndoa contém valor energético mais elevado que a polpa, variando de $476 \mathrm{kcal} / 100 \mathrm{~g}$ a $560 \mathrm{kcal} / 100 \mathrm{~g}$ (Vallilo et al. 1990, Almeida 1998, Takemoto et al. 2001), composta de lipídios (40,2\%), proteínas (29,6\%), fibras solúveis e menor quantidade de açúcares (Togashi \& Sgarbieri 1994).

No entanto, são encontradas algumas substâncias antinutricionais neste fruto, como tanino, ácido fítico e inibidor de tripsina. $O$ teor de tanino é elevado na polpa, não sendo detectado na semente (amêndoa), tanto crua quanto torrada. Este componente tende a decrescer com a maturação do fruto e o inibidor da tripsina pode ser inativado pela simples torragem da semente (Togashi \& Sgarbieri 1994).

Em relação à análise sensorial, esta é realizada em função das respostas transmitidas pelos indivíduos às várias sensações que se originam de reações fisiológicas e são resultantes de certos estímulos. Estas sensações produzidas podem dimensionar a intensidade, extensão, duração, qualidade, gosto ou desgosto, em relação ao produto avaliado (IAL 2005).

Assim, o presente trabalho teve como objetivo caracterizar a polpa do baru, por meio da composição centesimal, investigar a perda de alguns componentes do fruto, durante o armazenamento em diferentes condições, e desenvolver formulação de biscoitos com a polpa do baru, avaliando-os sensorialmente.

\section{MATERIAL E MÉTODOS}

Os frutos foram colhidos no mês de outubro de 2007, em uma comunidade de Pirenópolis, Estado de Goiás, quando iniciou-se sua queda natural, o que indicou o ponto ideal de colheita dos frutos. Para obtenção de material em estágios de maturação com alguma uniformidade, os ramos do barueiro foram sacudidos e recolhidos apenas os frutos que se desprenderam (Azzolini et al. 2004). Assim, foram colhidos 110 frutos, de 10 diferentes árvores, em uma mesma área.

As análises foram realizadas nos Laboratórios de Nutrição e Análise de Alimentos, de Dietética e de Análise Sensorial, da Faculdade de Nutrição da Universidade Federal de Goiás (UFG) e no laboratório de Análise de Alimentos da Embrapa Arroz e Feijão, localizado no município de Santo Antônio de Goiás (GO). 
Todas as análises foram realizadas em triplicata e os tratamentos com duas repetições, exceto a análise de fibras, que foi realizada em quatro replicatas.

Após a colheita, os frutos foram misturados e homogeneizados. Em seguida, foram higienizados com água corrente e, posteriormente, divididos em dois grupos (sanitizados - Tratamento 1 - e não sanitizados Tratamento 2) e acondicionados em caixas plásticas, com circulação de ar e devidamente higienizadas. Realizada a separação dos grupos, as amostras foram armazenadas à temperatura ambiente.

A sanitização dos frutos e caixas foi realizada utilizando-se solução de hipoclorito de sódio, a $200 \mathrm{mg} \mathrm{L}^{-1}$, por 15 minutos (Silva 2000).

A despolpa dos frutos aconteceu de forma manual, com auxílio de facas de mesa, retirandose, primeiramente, as cascas. Tal procedimento foi utilizado na tentativa de se garantir uma melhor qualidade sensorial da matéria-prima em questão. Durante as despolpas, procedeu-se à retirada das cascas, na íntegra, pois, segundo alguns autores, grande parte dos taninos, responsáveis pelo sabor adstringente do fruto, está presente na casca (Chang et al. 1994, Silva \& Silva 1999, Queiroz et al. 2002, Ferrão et al. 2003). Esta foi realizada em cada tempo, nos dias de cada análise, para acompanhamento da maturação dos frutos, por ser considerada inadequada a despolpa completa no início do experimento.

Durante os tempos de análise, características físicas dos frutos, como massa $(\mathrm{kg})$, comprimento $(\mathrm{mm})$ e largura ( $\mathrm{mm})$, foram analisadas, com auxílio de balança analítica e paquímetro digital.

As amostras com 1 e 136 dias de armazenamento foram submetidas à determinação da composição centesimal. A determinação da umidade foi realizada por secagem da amostra em estufa, a $105^{\circ} \mathrm{C}$, até massa constante, conforme descrição do Instituto Adolfo Lutz (1985). Os lipídios totais foram extraídos segundo técnica descrita por Bligh \& Dyer (1959) e, posteriormente, determinados por gravimetria. O teor de nitrogênio foi determinado pelo método de Kjeldahl e convertido em proteína bruta, utilizando-se o fator 6,25. O resíduo mineral fixo foi determinado utilizando-se o método de incineração, a $550^{\circ} \mathrm{C}$. O teor de fibra alimentar foi determinado por hidrólise enzimática (AOAC 1990) e os carboidratos totais pelo cálculo da diferença entre $100 \mathrm{~g}$ do alimento e a soma total dos valores encontrados para umidade, proteína, lipídios, fibra alimentar total e resíduo mineral fixo. O valor energético total dos alimentos foi estimado considerando-se os fatores de conversão de Atwater, de $9 \mathrm{kcal}$, para $1 \mathrm{~g}$ de lipídio, e $4 \mathrm{kcal}$, para $1 \mathrm{~g}$ de proteína e carboidrato, respectivamente (Brasil 2000).

A partir das amostras separadas, monitorouse, do $1^{\circ}$ ao $181^{\circ}$ dia de armazenamento, em sete períodos $(1 ; 16 ; 31 ; 46 ; 91 ; 136$; e 181), os seguintes componentes da polpa de baru: teor de taninos (Price et al. 1978), açúcares redutores e totais, cor, oxidação lipídica (IAL 2005) e análises microbiológicas, segundo as recomendações para frutos in natura (Brasil 2001). Os demais componentes diminuíram, gradativamente, durante a estocagem, ou originaramse de amostras que não apresentavam condições de análise.

Ao longo do estudo, as amostras de cada tempo foram estocadas a $-18^{\circ} \mathrm{C}$ e, ao final do experimento, foi realizada análise sensorial de biscoitos formulados com polpa e amêndoa do baru de três tempos diferentes (início, meio e fim do experimento), além do controle. A formulação do biscoito controle foi adaptada de formulação padronizada de biscoito seco de amêndoa (Docinhos e biscoitos 2007), a partir de massa constituída de farinha de trigo (250 g), açúcar cristal (250 g), amêndoas de baru (60 g), ovo (55 g), fermento químico em pó (10 g), essência de amêndoa ( $1 \mathrm{~g})$ e margarina vegetal (10 g). No biscoito experimental, foi realizada substituição de $25 \%$ da farinha de trigo por polpa de baru $(62,5 \mathrm{~g})$ e retirada a margarina da formulação do biscoito controle. Os demais ingredientes permaneceram constantes.

Realizou-se teste de aceitabilidade dos biscoitos, utilizando-se uma escala hedônica de 9 pontos, variando de "1 - desgostei muitíssimo" a "9 - gostei muitíssimo", para aparência e sabor. O teste foi realizado com 40 provadores não treinados, de ambos os sexos, frequentadores da Faculdade de Nutrição da Universidade Federal de Goiás.

Os dados experimentais obtidos das determinações analíticas, no mínimo em triplicata, foram avaliados por análise de variância e as diferenças entre as médias testadas a $5 \%$ de probabilidade, pelo teste Tukey, utilizando-se o programa Excel for Windows, versão 2003, e modelagem cinética dos mesmos, com o auxílio de curva polinomial de $2^{\mathrm{a}}$ ordem, para predizer a vida de prateleira da polpa do baru e, também, efetuar a avaliação da aceitabilidade do biscoito seco, elaborado como objeto em estudo. 


\section{RESULTADOS E DISCUSSÃO}

Como os frutos do Cerrado, em geral, apresentam grande variabilidade genética, o que influencia no delineamento de estratégias de conservação, a fim de garantir uma boa qualidade do fruto, durante o período de estocagem, optou-se pela metodologia de colheita mencionada anteriormente (Botezelli et al. 2000, Azzolini et al. 2004, Ribeiro \& Rodrigues 2006).

As amostras subdivididas foram colocadas em caixas plásticas, devido à sua capacidade de serem empilhadas sem causar danos mecânicos aos frutos e à sua fácil circulação de ar e aquisição, por parte das comunidades que sobrevivem deste fruto.

A alta variabilidade genética do baru deve-se, entre outros fatores, à alta dispersão dos frutos, por animais como o morcego (Sano et al. 2004), e este fato interfere em algumas de suas características, como massa e tamanho. No entanto, pôde-se observar que a massa praticamente não varia, ao longo do armazenamento, mantendo frutos não sanitizados e sanitizados com massa média de 40,86g e 44,35g, respectivamente.

Como pode ser observado na Tabela 1, o comprimento e a largura tiveram comportamento semelhante ao da massa, com o decorrer do tempo, não apresentando variações significativas $(p<0,05)$, durante os 90 dias de armazenamento, para todos os tratamentos. As pequenas variações que ocorreram provavelmente estejam relacionadas com as diferenças entre as amostras, além do aumento significativo de umidade, durante a estocagem. Tal comportamento pode estar associado à inevitável perda ou transformação dos constituintes do fruto, durante este período, bem como às condições ambientais de umidade, que foram modificando-se ao longo do experimento, afetando, significativamente, a quantidade de água livre na polpa do fruto.

A composição centesimal e o valor energético total da polpa de baru, recém-colhido e com 136 dias de armazenamento, encontram-se descritos na Tabela 2.

Quanto às quantidades de alguns componentes encontrados no baru, a polpa deste fruto apresenta, em geral, 3,5-10,13\% de proteína; 3,27-4,13\% de lipídios; e 1,79-2,99\% de cinzas. Quanto ao teor de

Tabela 2. Composição centesimal aproximada $(\mathrm{g} / 100 \mathrm{~g})$ e valor energético total (kcal) da polpa de baru, com 1 e 136 dias de armazenamento (Goiânia, GO, 2007).

\begin{tabular}{ccc}
\hline Componentes $^{1,2}$ & $\begin{array}{c}\text { Polpa } \\
(1 \text { dia armazenamento })\end{array}$ & $\begin{array}{c}\text { Polpa } \\
(136 \text { dias armazenamento })\end{array}$ \\
\hline Umidade & $13,76 \pm 0,57^{3}$ & $28,99 \pm 1,04$ \\
Proteínas & $4,17 \pm 0,70$ & $4,36 \pm 1,57$ \\
Lipídios totais & $3,73 \pm 0,14^{4}$ & $2,27 \pm 0,54$ \\
Fibra alimentar total & $19,10 \pm 0,20^{4}$ & $27,00 \pm 0,00$ \\
Cinzas & $4,34 \pm 0,30^{4}$ & $3,58 \pm 0,47$ \\
Carboidratos $^{3}$ & 54,90 & 33,8 \\
Valor energético $(\mathrm{kcal})$ & 269,85 & 173,07 \\
\hline
\end{tabular}

Valores constituem média \pm desvio-padrão de três replicatas, exceto para fibra alimentar total (quatro replicatas).

${ }^{2}$ Valores apresentados em base seca.

${ }^{3}$ Calculado por diferença, subtraindo-se de 100 os valores obtidos para umidade, proteínas, lipídios totais, fibra alimentar total e cinzas.

${ }^{4}$ Diferença significativa, pelo teste $t$ de Student, entre os tempos de armazenamento $(\mathrm{p}<0,05)$.

Tabela 1. Valores de massa (g), comprimento ( $\mathrm{mm}$ ) e largura ( $\mathrm{mm})$, durante 90 dias de armazenamento de frutos de baru sanitizados e não sanitizados (Goiânia, GO, 2007).

\begin{tabular}{|c|c|c|c|c|c|}
\hline \multirow{2}{*}{ Componentes ${ }^{1}$} & \multicolumn{5}{|c|}{ Tempos de armazenamento (dias) } \\
\hline & 0 & 15 & 30 & 45 & 90 \\
\hline \multicolumn{6}{|c|}{ Frutos sanitizados } \\
\hline Massa & $44,23 \pm 9,41^{2}$ & $43,55 \pm 12,44$ & $45,91 \pm 10,98$ & $43,87 \pm 9,61$ & $44,18 \pm 9,72$ \\
\hline Comprimento & $63,51 \pm 6,11$ & $62,75 \pm 8,42$ & $64,33 \pm 6,42$ & $62,72 \pm 6,65$ & $61,08 \pm 6,53$ \\
\hline Largura & $32,71 \pm 2,40^{2}$ & $32,34 \pm 3,47$ & $32,72 \pm 2,80$ & $32,02 \pm 2,68$ & $32,67 \pm 2,37$ \\
\hline \multicolumn{6}{|c|}{ Frutos não sanitizados } \\
\hline Massa & $38,11 \pm 9,36$ & $39,30 \pm 10,21$ & $45,58 \pm 10,38$ & $42,86 \pm 12,52$ & $38,47 \pm 9,04$ \\
\hline Comprimento & $61,17 \pm 7,98$ & $61,65 \pm 7,32$ & $63,01 \pm 6,16$ & $62,49 \pm 7,59$ & $60,34 \pm 7,36$ \\
\hline Largura & $31,30 \pm 2,64$ & $31,33 \pm 2,87$ & $32,91 \pm 2,83$ & $32,40 \pm 3,27$ & $30,92 \pm 2,32$ \\
\hline
\end{tabular}

${ }^{1}$ Valores apresentados como média \pm desvio-padrão.

${ }^{2}$ Diferença significativa, pelo teste $t$ de Student, entre os parâmetros de armazenamento $(\mathrm{p}<0,05)$. 
fibras, o baru é considerado um alimento rico em fibras, apresentando por volta de 19\% (Filgueiras \& Silva 1975, Almeida et al. 1990, Togashi \& Sgarbieri 1994, Togashi \& Sgarbieri 1995, Takemoto et al. 2001). Em relação ao valor energético total, alguns autores relatam que a polpa apresenta valor calórico de, aproximadamente, $300 \mathrm{kcal} / 100 \mathrm{~g}$ (Vallilo et al. 1990, Almeida 1998). Sendo assim, o valor encontrado na primeira composição centesimal $(269,85 \mathrm{kcal})$ mostra-se $10,05 \%$ inferior ao relatado por Almeida (1998), enquanto o valor da segunda composição centesimal $(173,07 \mathrm{kcal})$ apresenta-se $42,31 \%$ inferior aos dados da literatura. Isto se deve, provavelmente, à perda de alguns componentes, como lipídios e carboidratos, durante o armazenamento.

Entre as composições centesimais, pode-se observar que a proteína foi o único componente a se manter significativamente igual, ao longo de 136 dias de armazenamento. $\mathrm{O}$ aumento da umidade, de $13,76 \%$ para $28,99 \%$, se deve às condições ambientais que foram modificando-se, ao longo do experimento, afetando a quantidade de água na polpa do fruto e mostrando que este componente pode estar relacionado à estabilidade do alimento. $\mathrm{O}$ teor de cinzas diminuiu de $4,34 \%$ para $3,58 \%$, pela relação inversa com a umidade.

Já a quantidade de fibras aumentou de 19,10\% para $27 \%$, do primeiro para o sexto tempo de estocagem, pela transformação dos amidos presentes na polpa do baru em amidos resistentes, que foram detectados como fibras insolúveis (Kritchevsky et al. 1988). Durante o armazenamento, componentes químicos de um alimento vão se perdendo ou se transformando em outras substâncias, que determinam a vida útil do mesmo (Gava 1984).

A avaliação cinética dos barus, nos dois tratamentos, só foi possível ser realizada até o $5^{\circ}$ tempo de estocagem, uma vez que, ao chegar ao sexto tempo de armazenamento (135 dias), as polpas já não possuíam mais condições de consumo, devido à presença de fungos, perceptíveis a olho nu.

A polpa do baru é um alimento rico em açúcares, que aumentam com o tempo de estocagem, caracterizando a continuidade da maturação. Os açúcares totais correspondem a 7,3\% do peso do fruto, em base seca (Filgueiras \& Silva 1975, Almeida et al. 1990, Togashi \& Sgarbieri 1994, Togashi \& Sgarbieri 1995, Takemoto et al. 2001).

O teor de açúcares totais das polpas dos barus sanitizados, encontrado no início do estudo (22,70\%), mostrou-se próximo ao valor de 20,45\%, encontrado por Togashi \& Sgarbieri (1994), variando em 11\%. No entanto, no presente trabalho, os valores de açúcares redutores e totais continuaram aumentando, ao longo do período de armazenamento (Figuras 1 e 2). Quanto ao teor de açúcares totais, não houve diferença significativa $(p<0,05)$ entre os tratamentos (sanitizados e não sanitizados), mas houve diferença significativa entre os tempos de armazenamento, exceto entre o quarto e o quinto tempos.

Em relação aos açúcares redutores (Figura 2), tanto para as polpas de frutos sanitizados quanto para as de frutos sem sanitização, pôde-se observar aumento significativo, durante os 30 primeiros dias. Porém, não houve diferença significativa entre os tratamentos, mas entre os tempos de armazenamento, exceto entre o terceiro tempo (30 dias de armazenamento) e o quarto (45 dias), quando houve diferença significativa $(\mathrm{p}<0,05)$.

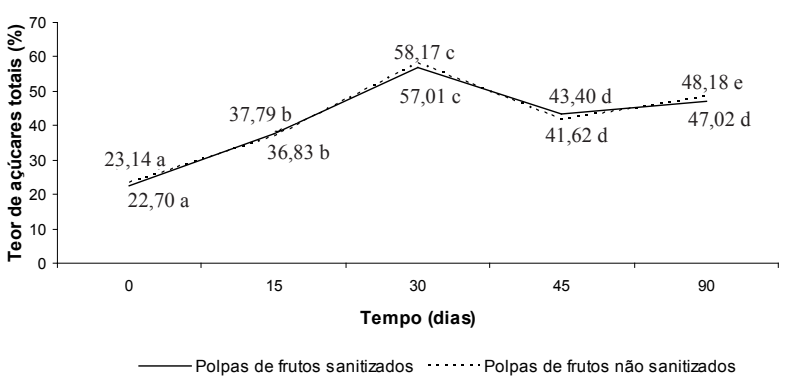

Figura 1. Variação do teor de açúcares totais (\%), durante 90 dias de armazenamento, em polpas de barus sanitizados e não sanitizados. ${ }^{a, b, c}$ Letras iguais não apresentam diferenças significativas, a $5 \%$ de probabilidade, pelo teste Tukey (Goiânia, GO, 2007).

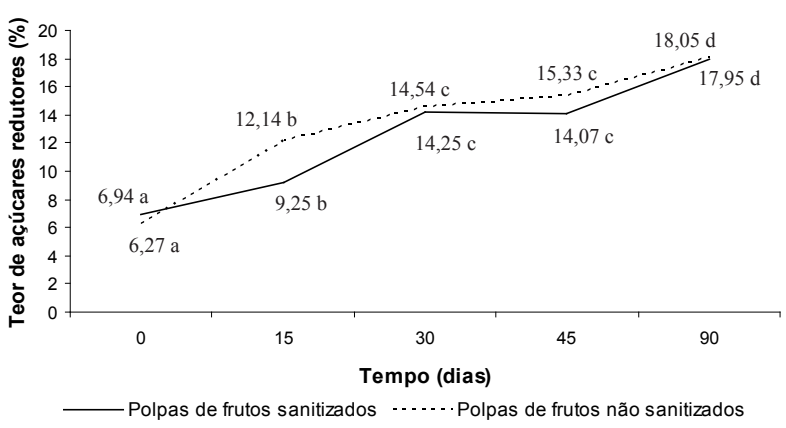

Figura 2. Variação do teor de açúcares redutores (\%), durante 90 dias de armazenamento, em polpas de barus sanitizados e não sanitizados. ${ }^{a, b, c}$ Letras iguais não apresentam diferenças significativas, a $5 \%$ de probabilidade, pelo teste Tukey (Goiânia, GO, 2007). 
O aumento de açúcares na polpa do baru pode estar relacionado com o teor de taninos (Figura 3), que diminui até acabar, ao longo dos 90 dias. Isto acontece pelo fato de os taninos terem sabor adstringente e, quando este composto não está mais presente no fruto, o sabor se torna mais adocicado (Sano et al. 2004, Togashi 1993).

Quanto ao teor de taninos, observou-se que a sanitização teve efeito benéfico, pois as polpas de frutos sanitizados apresentaram menores teores deste composto, sendo estas diferenças significativas. Isto se deve, provavelmente, ao fato de os taninos presentes no baru serem, em sua maioria, hidrossolúveis. Independentemente da higienização, o teor de taninos foi diminuindo, ao longo dos 30 primeiros dias de armazenamento (Figura 3), demonstrando que houve diferença significativa $(\mathrm{p}<0,05)$ entre os tempos de armazenamento, mas que, a partir do segundo tempo, não houve mais esta diferença, o que nos permite afirmar que este componente vai diminuindo ao longo do tempo, até acabar.

Em relação ao teste de aceitação de sabor dos biscoitos formulados com $25 \%$ de substituição da farinha de trigo pela polpa de baru, pôde-se observar (Figura 4) que todas as formulações apresentaram notas satisfatórias, ficando na escala analisada entre "gostei ligeiramente" e "gostei muito", o que demonstra boa aceitação do produto.

Em relação à aparência (Figura 4), os biscoitos não apresentaram diferença significativa entre as quatro formulações elaboradas $(p<0,05)$, tendo médias entre 6 e 7,5, assim como ocorreu com o sabor. Estes resultados também foram obtidos em estudo realizado por Soares Júnior et al. (2007), no qual foi adicionada farinha da

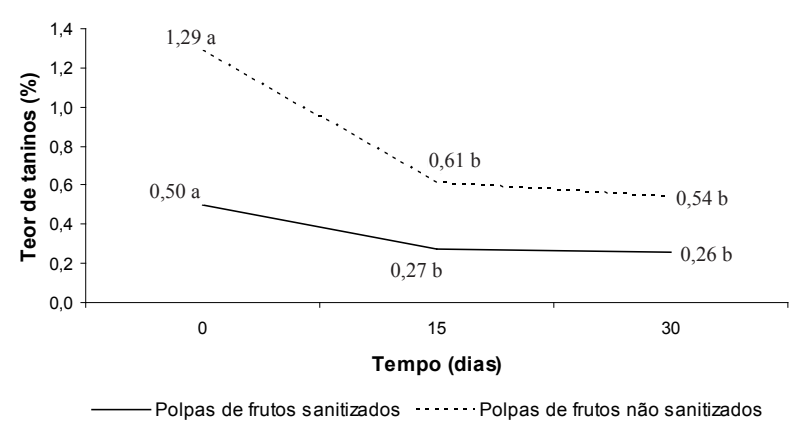

Figura 3. Variação do teor de taninos (\%), durante 30 dias de armazenamento, em polpas de barus sanitizados e não sanitizados. ${ }^{\mathrm{a}, \mathrm{b}, \mathrm{c}}$ Letras iguais não apresentam diferenças significativas, a $5 \%$ de probabilidade, pelo teste Tukey (Goiânia, GO, 2007).

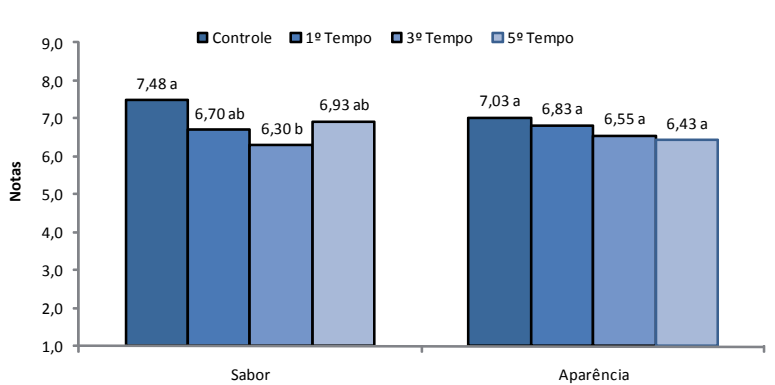

Figura 4. Variação de notas sobre sabor e aparência do biscoito seco de baru, com $25 \%$ de substituição da farinha de trigo pela polpa de baru. ${ }^{\text {a,b,c }}$ Letras iguais não apresentam diferenças significativas, a 5\% de probabilidade, pelo teste Tukey (Goiânia, GO, 2007).

amêndoa de baru, em substituição à farinha de trigo, em biscoitos tipo cookie, sem que fosse afetada a resistência à quebra, aparência, sabor e textura destes biscoitos, indicando boa aceitação do produto. Isto demonstra que farinhas provenientes dos frutos do Cerrado, tais como da amêndoa e polpa de baru, podem ser utilizadas sem perda da qualidade na formulação de biscoitos, sendo incentivado o uso de produtos regionais no desenvolvimento de alternativas alimentícias.

Em relação às informações nutricionais (Tabela 3), o valor energético do biscoito controle foi $8,4 \%$ superior ao valor energético do biscoito com $25 \%$ de substituição, pois a polpa de baru tem valor calórico inferior ao da farinha de trigo. A margarina, ingrediente de alto valor energético, não foi utilizada no biscoito com substituição da farinha de trigo pela polpa de baru, pois a massa adquiriu textura adequada sem a sua presença, provavelmente pelo alto teor de amidos contidos

Tabela 3. Valor nutricional dos biscoitos elaborados (Goiânia, GO, 2007).

\begin{tabular}{ccc}
\hline \multicolumn{3}{c}{ Informação nutricional - porção de $30 \mathrm{~g}$ (1 unidade) } \\
\hline & $\begin{array}{c}\text { Biscoito } \\
\text { controle }^{1}\end{array}$ & $\begin{array}{c}\text { Biscoito com 25\% } \\
\text { de substituição }\end{array}$ \\
\hline Valor energético & $114,8 \mathrm{kcal}$ & $105,9 \mathrm{kcal}$ \\
Carboidratos & $21,2 \mathrm{~g}$ & $20,8 \mathrm{~g}$ \\
Proteínas & $2,2 \mathrm{~g}$ & $2,2 \mathrm{~g}$ \\
Gorduras Totais & $2,3 \mathrm{~g}$ & $1,6 \mathrm{~g}$ \\
Fibra alimentar & $0,9 \mathrm{~g}$ & $1,7 \mathrm{~g}$ \\
Sódio & $107,3 \mathrm{mg}$ & $109,4 \mathrm{mg}$ \\
\hline
\end{tabular}

${ }^{1}$ Tabela Brasileira de Composição de Alimentos (NEPA 2006).

${ }^{2}$ Tabela Brasileira de Composição de Alimentos (NEPA 2006). Dados gerados na composição centesimal de polpa de baru, pelos autores do trabalho. 
na polpa do fruto. Este fato justifica, também, a redução de gorduras totais de $2,3 \mathrm{~g}$, no biscoito controle, para 1,6 g, no biscoito com $25 \%$ de substituição. Outro aspecto relevante foi o aumento das fibras alimentares, de $0,9 \mathrm{~g}$ (biscoito controle) para $1,7 \mathrm{~g}$ (biscoito com $25 \%$ de substituição), pois, no segundo biscoito, adicionou-se a polpa de baru, a qual é rica em fibras, quando comparada com a farinha de trigo.

No presente estudo, foi realizado apenas um grau de substituição da farinha de trigo pela polpa, haja vista que, nesta análise sensorial, aproximadamente $45 \%$ dos provadores perceberam, no biscoito formulado com a polpa do primeiro tempo de armazenamento, um sabor amargo. Com o aumento da percentagem de substituição, provavelmente este sabor residual se tornaria mais acentuado. Este residual amargo se deve, principalmente, aos taninos, ainda presentes nas polpas das duas primeiras formulações.

A partir desta análise sensorial, pode-se afirmar que o biscoito seco, elaborado com $25 \%$ de substituição, é um alimento vantajoso para as comunidades que sobrevivem deste fruto, sendo que, atualmente, a polpa do baru é descartada e o biscoito leva, em sua formulação, além da polpa, a amêndoa.

\section{CONCLUSÕES}

1. A avaliação, durante o experimento, demonstrou que o baru é um fruto climatérico, ou seja, que continua seu processo de maturação, mesmo após a colheita, e que a polpa do baru pode ser considerada importante fonte de fibra alimentar $(27 \%)$ e açúcares, contendo elevado teor de taninos, que diminui, gradativamente, até atingir valor 0 , com o aumento do grau de maturação do fruto.

2. A análise sensorial dos biscoitos com $25 \%$ de substituição da farinha de trigo pela polpa de baru demonstrou boa aceitação do produto, em relação à sua aparência e sabor, quando utilizados os frutos colhidos nas próprias comunidades. Além disso, o alimento apresentou valor energético considerável, baixo teor de gorduras e alto teor de fibras.

\section{AGRADECIMENTOS}

Ao Instituto de Educação do Brasil (IEB), pelo apoio financeiro, e à comunidade "Promessa de Futuro", localizada em Pirenópolis, Goiás, pela ajuda na aquisição e colheita dos frutos.

\section{REFERÊNCIAS}

ALMEIDA, S. P. Cerrado: aproveitamento alimentar. Planaltina: Embrapa-CPAC, 1998.

ALMEIDA, S. P.; SILVA, J. A.; RIBEIRO, J. F. Aproveitamento alimentar de espécies nativas dos Cerrados: araticum, baru, cagaita e jatobá. 2. ed. Planaltina: Embrapa-CPAC, 1990.

ASSOCIATION OF OFFICIAL AGRICULTURAL CHEMISTS (AOAC). Official methods of analysis. 15. ed. Washington, D.C.: AOAC, 1990.

AZEREDO, H. M. C.; FARIA, J. A. F. Fundamentos de cinética de degradação e estimativa de vida de prateleira. In: EMBRAPA. Fundamentos de estabilidade de alimentos. Fortaleza: Editora Técnica Henriette Monteiro Cordeiro de Azeredo, 2004. p. 77-95.

AZZOLINI, M.; JACOMINO, A. P.; BRON, I. U. Índices para avaliar qualidade pós-colheita de goiabas em diferentes estádios de maturação. Pesquisa Agropecuária Brasileira, Brasília, DF, v. 39, n. 2, p. 139-145, 2004.

BLIGH, E. G.; DYER, W. J. A rapid method of total lipid extraction and purification. Canadian Journal of Biochemistry and Physiology, Ottawa, v. 37, n. 8, p. 911917, 1959.

BOTEZELLI, L.; DAVIDE, A. C.; MALAVASI, M. M. Características dos frutos e sementes de quatro procedências de Dipteryx alata Vogel (baru). Cerne, Lavras, v. 6, n. 1, p. 9-18, 2000.

BRASIL. Agência Nacional de Vigilância Sanitária. Resolução de Diretoria Colegiada no 94 de 2000. Aprova o regulamento técnico para rotulagem obrigatória de alimentos e bebidas embalados. Diário Oficial da República Federativa do Brasil, Brasília, DF, 01 nov. 2000. Disponível em: $<$ http://www.anvisa.gov.br/e-legis/>. Acesso em: 10 jul. 2008.

BRASIL. Agência Nacional de Vigilância Sanitária. Resolução de Diretoria Colegiada $\mathrm{n}^{\circ} 12$ de 2001. Aprova o regulamento técnico sobre os padrões microbiológicos para alimentos. Diário Oficial da República Federativa do Brasil, Brasília, DF, 02 jan. 2001. Disponível em: < http:// www.anvisa.gov.br >. Acesso em: 13 mar. 2008.

CHANG, M. J. et al. Cowpeas tannins related to cultivar, maturity, dehulling and heating. Journal of Food Science, Chicago, v. 59, n. 5, p. 1034-1036, 1994.

DOCINHOS e biscoitos. A Grande Cozinha, São Paulo, v. 16, p. 176, 2007.

FERRÃO, M. F. et al. Técnica não destrutiva de análise de tanino em café empregando espectroscopia no infravermelho e algoritmo genético. Tecno-lóg, Santa Cruz do Sul, v. 7, n. 1, p. 9-26, 2003. 
FILGUEIRAS, T. S.; SILVA, E. Estudo preliminar do baru (Leg. Faboideae). Brasil Florestal, Brasília, DF, v. 6, n. 1, p. 33-39, 1975.

GAVA, A. J. Princípios de tecnologia de alimentos. São Paulo: Nobel, 1984.

INSTITUTO ADOLFO LUTZ (IAL). Métodos físicoquímicos para análise de alimentos. 4. ed. Brasília, DF: Ministério da Saúde, 2005.

INSTITUTO ADOLFO LUTZ (IAL). Normas analíticas do Instituto Adolfo Lutz: métodos químicos e físicos para análise de alimentos. 3. ed. São Paulo: IAL, 1985.

KRITCHEVSKY, D.; BONFIELD, C.; ANDERSON, J. W. Dietary fiber. Washington, D.C.: Plenum Press, 1988.

NÚCLEO DE ESTUDOS E PESQUISAS EM ALIMENTAÇÃO (NEPA). Tabela brasileira de composição de alimentos - TACO. 2. ed. Campinas: NEPA/Unicamp, 2006.

PRICE, M. L.; VAN SCOYOC, S.; BUTLER, L. G. A critical evaluation of the vanillin reaction as an assay for tannin in sorghum grain. Journal of Agricutural Food Chemistry, Washington, D.C., v. 26, n. 5, p. 1214-1218, 1978.

QUEIROZ, C. R. A. A.; MORAIS, S. L; NASCIMENTO, E. A. Caracterização dos taninos da aroeira-preta. Revista Árvore, Viçosa, v. 26, n. 4, p. 485-492, 2002.

RIBEIRO, R. A.; RODRIGUES, F. M. Genética da conservação em espécies vegetais do Cerrado. Ciências Médicas e Biológicas, Salvador, v. 5, n. 3, p. 253-260, 2006.

ROCHA, L. S. Caracterização físico-química, microbiológica e sensorial de pães de fôrma elaborados com subprodutos de baru (Dipteryx alata Vog.). 2007. 52 f. Dissertação (Mestrado em Ciência e Tecnologia de Alimentos)-Universidade Federal de Goiás, Goiânia, 2007.
SANO, S. M.; RIBEIRO, J. P.; BRITO, M. A. Baru: biologia e uso. Planaltina: Embrapa Cerrados, 2004. (Documentos, 116).

SILVA, J. A. Tópicos da tecnologia de alimentos. São Paulo: Livraria Varela, 2000.

SILVA, M. R.; SILVA, M. A. A. P. Aspectos nutricionais de fitatos e taninos. Revista de Nutrição, Campinas, v. 12, n. 1, p. 5-19, 1999.

SOARES JÚNIOR, M. S. et al. Qualidade de biscoitos formulados com diferentes teores de farinha de amêndoa de baru (Dipteryx alata Vog.). Pesquisa Agropecuária Tropical, Goiânia, v. 37, n. 1, p. 51-56, 2007.

TAKEMOTO, E. et al. Composição química da semente e do óleo de baru (Dipteryx alata Vog.) nativo do município de Pirenópolis, Estado de Goiás. Revista do Instituto Adolfo Lutz, São Paulo, v. 60, n. 2, p. 113-117, 2001.

TOGASHI, M. Composição e caracterização química e nutricional do fruto do baru (Dipteryx alata Vog.). 1993. 108 f. Dissertação (Mestrado em Engenharia de Alimentos)-Faculdade de Engenharia de Alimentos, Universidade Estadual de Campinas, Campinas, 1993.

TOGASHI, M.; SGARBIERI, V. C. Avaliação nutricional da proteína e do óleo de sementes de baru (Dipteryx alata Vog). Ciência e Tecnologia de Alimentos, Campinas, v. 15, n. 1, p. 66-69, 1995.

TOGASHI, M.; SGARBIERI, V. C. Caracterização química parcial do fruto do baru. Ciência e Tecnologia de Alimentos, Campinas, v. 14, n. 1, p. 85-95, 1994.

VALLILO, M. I.; TAVARES, M.; AUED, S. Composição química da polpa e da semente do fruto de cumbaru (Dipteryx alata Vog.): caracterização do óleo e da semente. Revista do Instituto Florestal, São Paulo, v. 2, n. 2, p. 115$125,1990$. 